\title{
POSITIVE SOLUTIONS FOR DISCRETE ANISOTROPIC EQUATIONS
}

\author{
ABDESSLEM AYOUJIL, MOHAMMED BERRAJAA, and BRAHIM OUHAMOU
}

\begin{abstract}
Using variational method, we study the existence of positive solutions for an anisotropic discrete Dirichlet problem with some functions $\alpha, \beta$ and a nonlinear term $f$.
\end{abstract}

MSC 2010. 35B38, 47A75, 35P30, 34L05, 34L30.

Key words. Discrete nonlinear boundary value problem, variational method, Ekeland's variational principle, mountain pass theorem, positive solution.

\section{REFERENCES}

[1] R.P. Agarwal, Difference Equations and Inequalities, Marcel Dekker Inc., New York, 2000 .

[2] R.P. Agarwal, K. Perera and D. O'Regan, Multiple positive solutions of singular and nonsingular discrete problems via variational methods, Nonlinear Anal., 58 (2004), 6973.

[3] Agarwal, Ravi P., Kanishka Perera, and Donal O'Regan, Multiple positive solutions of singular discrete p-Laplacian problems via variational methods, Adv. Difference Equ., 2005, 2, 93-99.

[4] A. Ayoujil, On class of nonhomogeneous discrete Dirichlet problems, Acta Univ. Apulensis Math. Inform., 39 (2014), 1-15.

[5] A. Ayoujil, On class of discrete boundary value problem via variational methods, Afr. Mat., 26 (2015), 7-8, 1349-1357.

[6] Bonanno, G., and Candito, P, Nonlinear difference equations investigated via critical point methods, Nonlinear Anal., 70 (2009), 9, 3180-3186.

[7] X. Cai and J. Yu, Existence theorems for second-order discrete boundary value problems, J. Math. Anal., 320 (2006), 649-661.

[8] I. Ekland, On the variational principale, J. Math. Anal. Appl., 47 (1974), 324-353.

[9] M. Galewski, S. Glab and R. Wieteska, Positive solutions for anisotropic discete boundary-value problems, Electron. J. Differential Equations, 2013, 32, 1-9.

[10] M. Galeski and S. Glab, New insights into Bazilevič maps, Math. Anal. Appl., 386 (2012), 2, 956-965.

[11] M. Galewski and R. Wieteska, Existence and multiplicity of positive solutions for discrete anisotropic equations, Turkish J. Math., 38 (2014), 2, 297-310.

[12] M. Galewski and R. Wieteska, On the system of anisotropic discrete BVPs, J. Difference Equ. Appl., 19 (2013), 7, 1065-1081.

[13] M. Galewski and J. Smejda, New insights into Bazilevič maps, J. Appl. Math. Comput., 219 (2013), 5963-5971.

DOI: 10.24193/mathcluj.2020.2.01 
[14] S.Heidarkhani, G. A.Afrouzi, S.Moradi and G. Caristi, Existence of multiple solutions for a perturbed discrete anisotropic equation, J. Difference Equ. Appl., 23 (2017), 9, 1491-1507.

[15] E.M. Hssini, Multiple solutions for a discrete anisotropic $\left(p_{1}(k), p_{2}(k)\right)$ Laplacian equations, Electron. J. Differential Equations, 2015 , 195, 1-10.

[16] B. Kone and S. Ouaro, Weak solutions for anisotropic discrete boundary value problems, J. Difference Equ. Appl., 17 (2011), 10, 1537-1547.

[17] R. Steglinski, On the sequence of large solutions for discrete anisotropic equations, Electron. J. Qual. Theory Differ. Equ., 2015, 25, 1-10.

[18] J. Mawhin, Problèmes de Dirichlet variationnels non linéaires, Les Presses de l'Université de Montréal, 1987.

[19] M. Mihăilescu, V. Rădulescu and S. Tersian, Eigenvalue problems for anisotropic discrete boundary value problems, J. Difference Equ. Appl., 15 (2009), 6, 557-567.

[20] Y. Tian, Z. Du and W. Ge Existence results for periodic Sturm-Liouville problem via variational methods, J. Difference Equ. Appl., 13 (2007), 6, 467-478.

Received April 27, 2019

Accepted October 16, 2019
Regional Centre of Trades Education and Training Department of Mathematics Oujda, Morocco

E-mail: abayoujil@gmail.com

University Mohamed I, Faculty of sciences Department of Mathematics

Oujda, Morocco

E-mail: berrajaamo@yahoo.fr

E-mail: ouhamoubrahim@gmail.com 